\title{
The comparison of aggregation and folding of enhanced green fluorescent protein (EGFP) by spectroscopic studies
}

\author{
Joanna Krasowska $^{\text {a }}$, Monika Olasek ${ }^{\mathrm{a}}$, Agnieszka Bzowska ${ }^{\mathrm{a}}$, Patricia L. Clark ${ }^{\mathrm{b}}$ \\ and Beata Wielgus-Kutrowska ${ }^{\mathrm{a}, *}$ \\ ${ }^{a}$ Department of Biophysics, Institute of Experimental Physics, University of Warsaw, Warsaw, Poland \\ ${ }^{\mathrm{b}}$ Department of Chemistry and Biochemistry, University of Notre Dame, Notre Dame, IN, USA
}

\begin{abstract}
GFP (Green Fluorescent Protein) is well known for its unique chromophore which is formed by autocatalytic cyclization of a polypeptide backbone of Ser65, Tyr66 and Gly67, and is able to emit green visible light. Due to unusual chromophore responsible for the fluorescence GFP and its mutants (e.g., EGFP) have become widely used reporter proteins in molecular biology and biotechnology. GFP can easily be fused to any protein of interest and co-expressed in cells; the GFP fluorescence is then used to visualize the distribution, transport and aggregation of the protein in the cell. However, GFP has a tendency to aggregate itself, and also formation of its chromophore critically depends on the presence of reducing agents. Therefore we have undertaken spectroscopic kinetic studies of EGFP folding and aggregation as a function of $\mathrm{pH}$, and in the presence of various reducing agents, to study the competition between these two processes. The best conditions for folding of EGFP provides BME as a reducing agent. Aggregation of EGFP depends strongly on $\mathrm{pH}$, and on the concentration of the protein. The careful control experiments must therefore be performed during investigations of proteins fused with EGFP, especially at pH lower than 7.

Keywords: GFP, folding, aggregation, fluorescence, light scattering, reducing agent
\end{abstract}

\section{Introduction}

The promotion of productive protein folding, and the suppression of competing, off-pathway aggregation processes, are in major medicinal, biochemical and biotechnological interest. Various methodologies have been developed to investigate protein aggregation and to find conditions that best stabilize native protein structures and therefore inhibit aggregation. This is mostly due to the evidence that a range of disorders from cataracts to Alzheimer and Parkinson diseases [3] are connected with the failure of cellular protein folding mechanisms. Moreover, insoluble protein aggregates cause problems in the production and purification of large amounts of proteins during their overexpression in bacterial or yeast cells [9].

Due to its intrinsic fluorescence, GFP has become a widely used reporter protein in molecular biology and biotechnology. It can be easily fused to any protein of interest and co-expressed in cells; the GFP

\footnotetext{
* Corresponding author: Beata Wielgus-Kutrowska, Department of Biophysics, Institute of Experimental Physics, University of Warsaw, Żwirki i Wigury 93, Warsaw, 02-089, Poland. Tel.: +48 225540 789; Fax: +48 225540 771; E-mail: beata@biogeo.uw.edu.pl.
} 
fluorescence is then used to visualize the distribution, transport and aggregation of the protein in the cell [2]. However GFP also has a tendency to aggregate, and formation of its chromophore is a slow process depending strongly on various parameters. Therefore we decided to study competition between folding and aggregation of GFP, and effects of various reducing agents on the chromophore maturation.

We have chosen EGFP, which has a 6-fold greater brightness than the wild type GFP [2,6]. It has two point mutations near the chromophore region: S65T simplifies the absorption spectrum of the chromophore and F64L enhances the fluorescence. We have performed a study of the folding and aggregation properties of EGFP by monitoring changes in tryptophan and chromophore fluorescence emission, and light scattering, as a function of concentration of a protein and as a function of $\mathrm{pH}$.

\section{Materials and methods}

S65T/F64L-GFP was prepared using Stratagene QuickChange mutagenesis kit. Unfolded protein was obtained by overexpression in E. coli strain BL21(DE3) [5] solubilisation of inclusion body in $6 \mathrm{M}$ $\mathrm{GdnHCl}, 50 \mathrm{mM}$ phosphate $\mathrm{pH} 8$ and $300 \mathrm{mM} \mathrm{NaCl}$ and purification on a Ni-NTA column. EGFP was concentrated using Millipore Amicon Ultra-4 centrifugal filter device and stored in phosphate with $6 \mathrm{M}$ $\mathrm{GdnHCl}$ and $300 \mathrm{mM} \mathrm{NaCl}$.

All reagents were of analytical grade. $\mathrm{GdnHCl}, \mathrm{NaCl}, \mathrm{HCl}$ and DTT were purchased from Roth, MESNA (sodium 2-mercaptoethane sulfonate), TCEP (tris(2-carboxyethyl) phosphine), $\mathrm{NaH}_{2} \mathrm{PO}_{4}$ and $\mathrm{Na}_{2} \mathrm{HPO}_{4}$ were from Sigma, BME (2-mercaptoethanol) was from BioRad and 2-ethanethiol was from Fluka.

Buffers for $\mathrm{pH}$ measurements consisted of $50 \mathrm{mM}$ mixture of $\mathrm{NaH}_{2} \mathrm{PO}_{4}, \mathrm{Na}_{2} \mathrm{HPO}_{4}, 300 \mathrm{mM} \mathrm{NaCl}$ and a reducing agent (mainly $\mathrm{BME}$ ). $\mathrm{HCl}$ was added to reach the $\mathrm{pH} 1$. Concentration of protein in the sample was in the range 2.5-10 $\mu \mathrm{M}$. For $\mathrm{pH}$-dependence of folding and aggregation measurements the protein was diluted in the $50 \mathrm{mM}$ phosphate $\mathrm{pH} 1$ and $300 \mathrm{mM} \mathrm{NaCl}$, and next the $\mathrm{GdnHCl}$ was removed by dialysis.

Absorption experiments were carried out at room temperature on Uvikon 933 (Kontron) or UV-VIS Cary 100Bio (Varian). Fluorescence emission and scattering studies were carried out on Perkin Elmer LS55 spectrophotometer. For tryptophan emission spectra excitation was at 280 or $295 \mathrm{~nm}$, and emission was observed in the range 290 or $300-550 \mathrm{~nm}$. For chromophore observation, the excitation was at $445 \mathrm{~nm}$ and emission was followed in the range $455-550 \mathrm{~nm}$. For each measurement three independent spectra were recorded, corrected for buffer emission, and averaged. Inner filter effect was negligible and can be neglected.

In folding kinetics studies, protein solution $\mathrm{pH} 1$ was mixed with the appropriate folding solution giving the final $\mathrm{pH}$ value $6.5,7$ and 8 . The kinetics of folding was followed by the tryptophan fluorescence (excitation at $280 \mathrm{~nm}$, emission at $310 \mathrm{~nm}$ ), and by the chromophore fluorescence (excitation at $489 \mathrm{~nm}$, emission at $509 \mathrm{~nm}$ ). Light scattering was measured at $640 \mathrm{~nm}$ (excitation and emission wavelength).

We have noticed that the addition of EGFP into the cuvette (or another vessel) filled with buffer causes higher light scattering (aggregation) of protein than the fast dilution of the protein by adding much higher volume of buffer into cuvette with protein. In our experiments we used the second method of diluting the sample. 


\section{Results}

\subsection{Reducing conditions}

It is well known that proper folding of the GFP-type proteins and chromophore maturation can proceed only in the presence of reducing agent. DTT is most often used. EGFP has 2 cysteine residues, both of which are reduced in the native structure, so reductants prevent non-native disulfide bond formation, either intra- or inter-molecular [8]. Without a reductant, the chromophore is not formed. However DTT gets oxidized in time. Absorption maximum of oxidized DTT is $283 \mathrm{~nm}$, very close to the protein absorption maximum at $278 \mathrm{~nm}$. Therefore it was necessary to find another reducing agent, more stable, for which the absorption spectrum in the range of absorption the aromatic aminoacids in protein is not changing during the time of experiment (typically a few days).

The specific reductant can affect the efficiency of chromophore formation upon folding. Under "folding efficiency" one must therefore consider both the ultimate maximal intensity of chromophore emission and also the rate of chromophore maturation. We have tested DTT, ethanethiol, MESNA, BME and TCEP. Optimal efficiency is achieved by folding EGFP in the presence of a relatively high $(70 \mathrm{mM})$ concentration of BME. The use of DTT as a reducing agent also resulted in efficient EGFP folding. Ethanethiol, MESNA and TCEP were much less effective (Fig. 1). BME as a reductant was used in next experiments, and it was found that it does affect neither the EGFP tryptophan emission spectrum nor the aggregation profile.

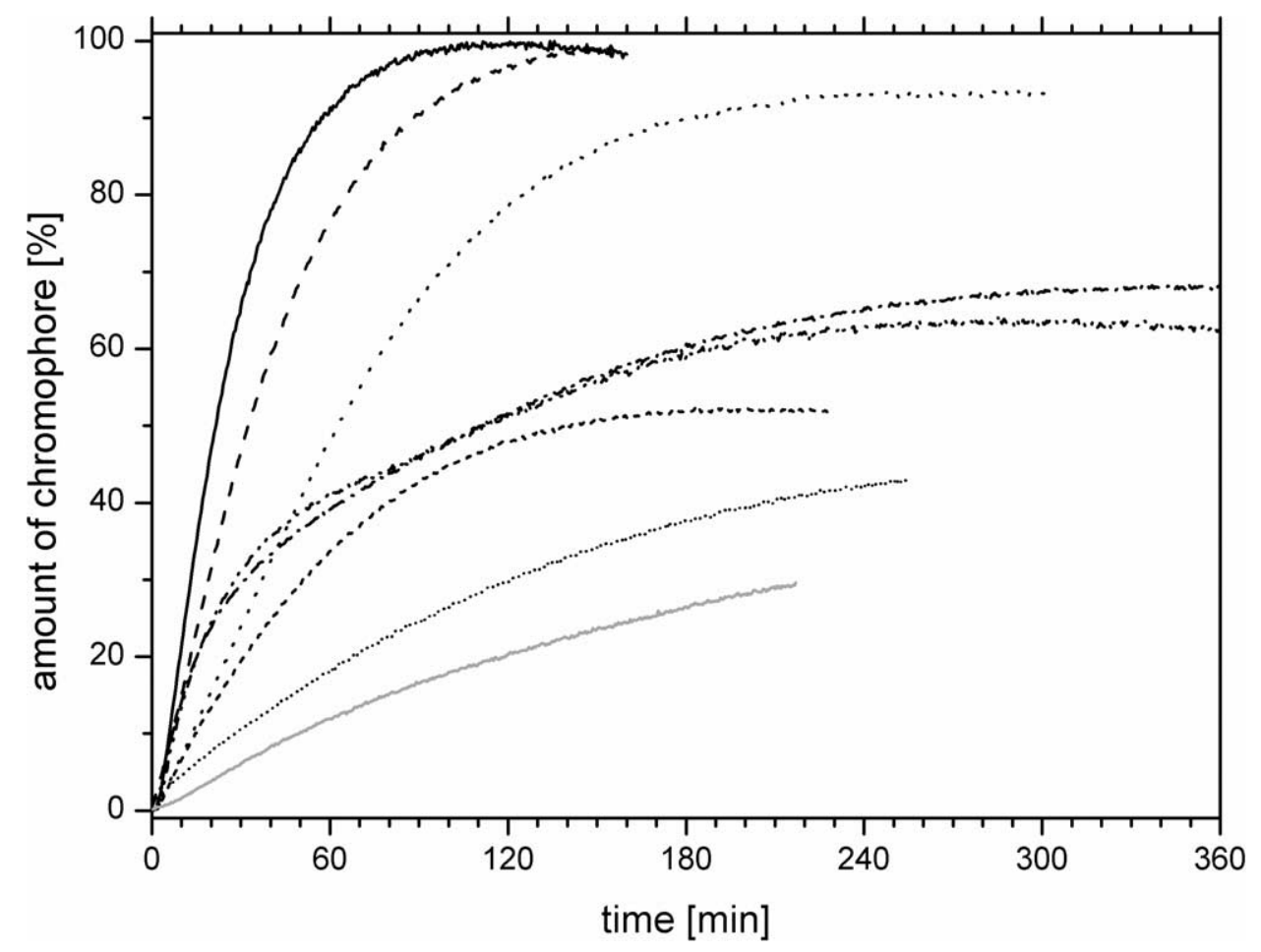

Fig. 1. Efficiency of the chromophore formation in various reducing conditions. The reducing agents used are: 2-mercaptoethanol 70 (solid line), 28 (dashed line) and $14 \mathrm{mM}$ (dotted line); DTT 20 (dash dot) and $10 \mathrm{mM}$ (dash dot dot); ethanethiol at $2 \% \mathrm{v} / \mathrm{v}$ (short dash); $1 \mathrm{mM}$ TCEP (short dot); $0.1 \mathrm{M}$ MESNA (solid grey). 


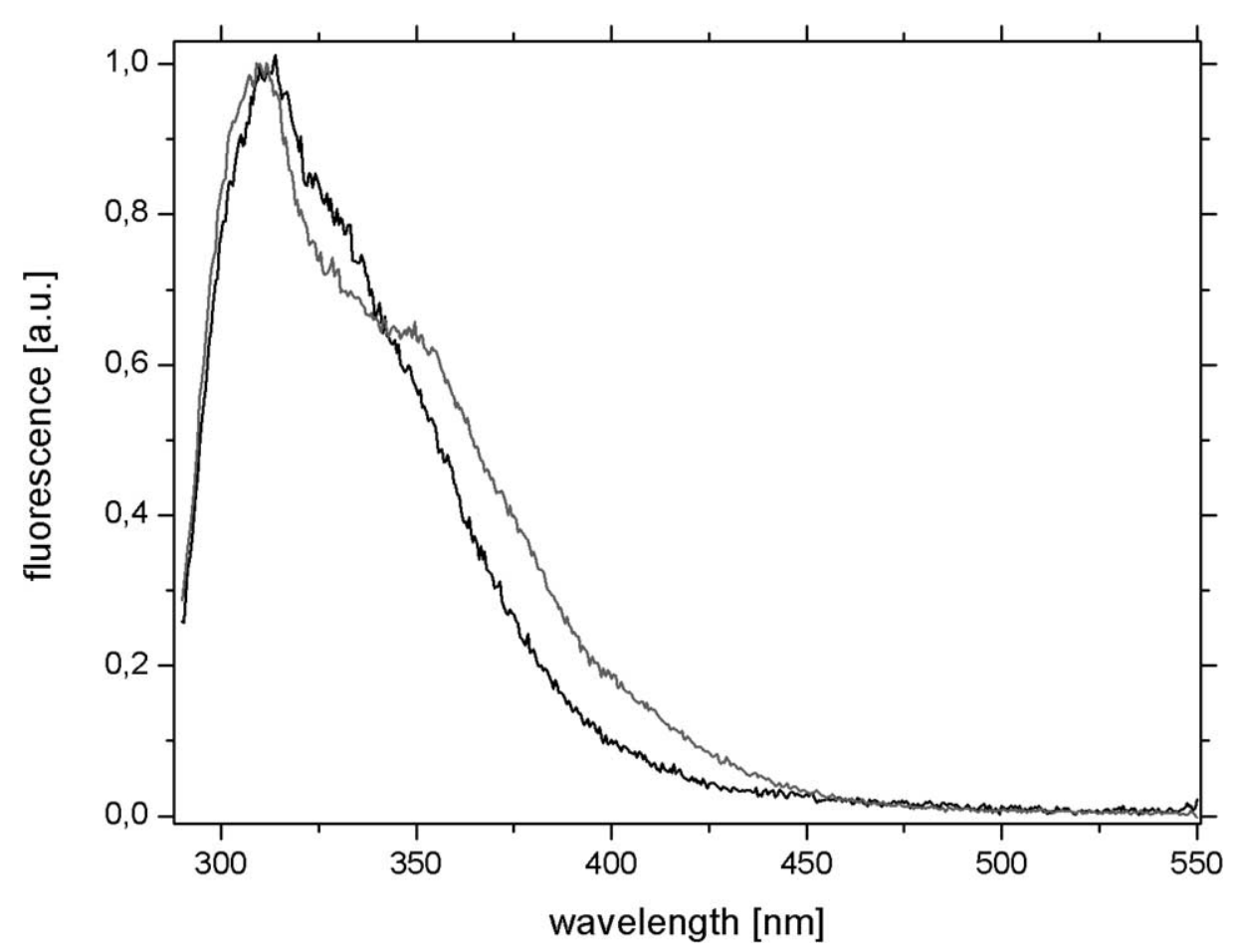

Fig. 2. The emission spectrum of the never folded EGFP suspended in buffer $\mathrm{pH} 1$ (black line), and in buffer pH 1 with $6 \mathrm{M}$ $\mathrm{GdnHCl}$ (grey line) for excitation at $280 \mathrm{~nm}$.

\subsection{The state of protein in $\mathrm{pH} 1$}

To check the state of EGFP at $\mathrm{pH} 1$ we have compared the emission spectrum of the never folded EGFP suspended in buffer $\mathrm{pH} \mathrm{1}$, and in buffer $\mathrm{pH} 1$ with $6 \mathrm{M} \mathrm{GdnHCl}$. In both cases the maximum of emission is at $305 \mathrm{~nm}$, but the shape of spectra are slightly different. Additional inflection at $355 \mathrm{~nm}$ is observed only for GFP in $6 \mathrm{M} \mathrm{GdnHCl} \mathrm{(Fig.} \mathrm{2).}$

The states of EGFP never folded suspended in buffer $\mathrm{pH} 1$, and never folded, suspended in buffer pH 1 with $6 \mathrm{M} \mathrm{GdnHCl}$ probably are slightly different because EGFP exists as a more compact structure at $\mathrm{pH} 1$ in the absence of $\mathrm{GdnHCl}$ than in $6 \mathrm{M} \mathrm{GdnHCl}, \mathrm{pH} 1$. A similar effect at $\mathrm{pH} 2$ was previously described for mutant Cycle3 [4]. Therefore the observation of folding and aggregation processes of aciddenatured EGFP begins probably a step later than in the case of the protein chemically denatured with 6 $\mathrm{M}$ GdnHCl.

\subsection{Aggregation of EGFP}

We have measured the light scattering at $640 \mathrm{~nm}$ as an indicator of aggregate formation at various $\mathrm{pH}$. As a control, the scattering of EGFP stored at $\mathrm{pH} 1$ was measured; in this case the signal corrected for the buffer scattering was close to 0 .

The folding and aggregation of EGFP was started by jump from $\mathrm{pH} 1$ to higher $\mathrm{pH}: 6.5,7$ or 8 . The strongest scattering is observed at $\mathrm{pH}$ about 6.5, probably due to increased precipitation at $\mathrm{pH}$ close to the protein $\mathrm{pI}=6.03$ [1]. With increasing $\mathrm{pH}$, the light scattering signal becomes less intensive. It indicates that in higher $\mathrm{pH}$ conditions become more favorable for proper folding. 
The rate of aggregation shows strong dependence on $\mathrm{pH}$ and is slower at $\mathrm{pH} 7$ and 8 than at $\mathrm{pH} 6.5$. After first $1000 \mathrm{~s}$ aggregated $8 \%, 24 \%$ and $74 \%$ of the sample with initial concentration of EGFP $2.5 \mu \mathrm{M}$, $13 \%, 25 \%$ and $78 \%$ with initial concentration $5 \mu \mathrm{M}$, and $23 \%, 34 \%$ and $95 \%$ with initial concentration $10 \mu \mathrm{M}$ at $\mathrm{pH} 8,7$ and 6.5, respectively (Table 1). The process of aggregation at $\mathrm{pH} 6.5$ is fast, well described by two-exponential equation and reaches a plateau after $5000 \mathrm{~s}$, while the aggregation at $\mathrm{pH} 7$ and 8 is nearly linear over this time period. The subsequent measurements have shown that this process reached the plateau after more than $48 \mathrm{~h}$ at $\mathrm{pH}$ 7, and more than $120 \mathrm{~h}$ at $\mathrm{pH} 8$ (data not shown).

To check the structure of aggregates the Congo red, an organic dye that binds specifically to amyloidlike aggregates was used. The binding of Congo red is visible as green birefringence in polarized light or as a red shift in absorbance spectrum. We have performed both assays. Green birefringence was visible in neither of the samples. The red shift of the absorption spectrum was also not observed. The results indicate that the aggregates are not regular (are not amyloid-like). They are probably amorphous.

\subsection{Efficiency of folding}

The chromophore formation was observed using fluorescence and absorption monitoring. The fluorescence of EGFP at $\mathrm{pH} 6.5$ was lower than at $\mathrm{pH} 7$ and 8 . The reason is not only the aggregation but also the presence of the neutral form of EGFP since $\mathrm{pK}_{\mathrm{a}}$ of the chromophore is 5.98 [7].

At $\mathrm{pH} 7$ the fluorescence reached plateau more slowly than at $\mathrm{pH} 6.5$ but the fluorescence was much stronger (data not shown). At pH 8 the maximum is highest (data not shown) but it was reached after about $24 \mathrm{~h}$.

The total efficiency of folding after $24 \mathrm{~h}$ (determined after removing the aggregates by centrifugation) was measured by the absorption at $489 \mathrm{~nm}$. The calculations of the properly folded EGFP concentration shows that in the solution remains $9 \%, 6.5 \%$ and $3.5 \%$ of the folded EGFP at $\mathrm{pH} 7$, and $28 \%, 22 \%$ and $12 \%$ at $\mathrm{pH} 8$, in the case of 2.5, 5 and $10 \mu \mathrm{M}$ initial concentration of EGFP, respectively (Table 2).

Table 1

Efficiency of aggregation as a function of $\mathrm{pH}$ and concentration of EGFP measured after first $1000 \mathrm{~s}$ of the process

\begin{tabular}{lccc}
\hline & \multicolumn{3}{c}{ EGFP concentration } \\
\cline { 2 - 4 } & $2.5 \mu \mathrm{M}(\%)$ & $5 \mu \mathrm{M}(\%)$ & $10 \mu \mathrm{M}(\%)$ \\
\hline pH 6.5 & 74 & 78 & 95 \\
pH 7 & 24 & 25 & 34 \\
pH 8 & 8 & 13 & 23 \\
\hline
\end{tabular}

Table 2

Efficiency of folding as a function of $\mathrm{pH}$ and concentration of EGFP measured after $24 \mathrm{~h}$ of the process

\begin{tabular}{lccc}
\hline & \multicolumn{3}{c}{ EGFP concentration } \\
\cline { 2 - 4 } & $2.5 \mu \mathrm{M}(\%)$ & $5 \mu \mathrm{M}(\%)$ & $10 \mu \mathrm{M}(\%)$ \\
\hline $\mathrm{pH} 7$ & 9 & 6.5 & 3.5 \\
$\mathrm{pH} 8$ & 28 & 22 & 12 \\
\hline
\end{tabular}




\section{Conclusions}

The best conditions for folding of EGFP provides BME at the relatively high concentration. The BME does affect neither the EGFP tryptophan emission spectrum nor the aggregation profile.

EGFP at $\mathrm{pH} 1$ probably exists as a more compact structure than in $6 \mathrm{M} \mathrm{GdnHCl,} \mathrm{pH} 1$. In the first case local environment of the tryptophan residue could be more similar to that in the native structure.

Aggregation of EGFP depends strongly on $\mathrm{pH}$ and on the concentration of protein. The careful control experiments must therefore be performed during investigations of proteins fused with EGFP, especially at low $\mathrm{pH}$. The aggregation of EGFP strongly competes and proceeds simultaneously with folding.

\section{Acknowledgement}

Supported by the Polish Ministry of Science and Higher Education (Grant No. N N302 118135).

\section{References}

[1] Calculated for histidine-taged EGFP using the ProtParam tool from the Expasy web site.

[2] M. Chalfie and S. Kain, eds, Green Fluorescent Protein - Properties and Applications, Wiley, New York, 1998, pp. 61-65.

[3] C.M. Dobson, Protein aggregation and its consequences for human disease, Protein Pept. Lett. 13 (2006), $219-227$.

[4] S. Enoki, K. Saeki, K. Maki and K. Kuwajima, Acid denaturation and refolding of green fluorescent protein, Biochemistry 43 (2004), 14238-14248.

[5] H. Fukuda, M. Arai and K. Kuwajima, Folding of green fluorescent protein and the cycle 3 mutant, Biochemistry 39 (2000), 12025-12032.

[6] G.H. Patterson, S.M. Knobel, W.D. Sharif, S.R. Kain and D.W. Piston, Use of green fluorescent protein and its mutants in quantitative fluorescence microscopy, Biophys. J. 73 (1997), 28782-28790.

[7] J.A. Sniegowski, M.E. Phail and R.M. Wachter, Maturation efficiency, trypsin sensitivity, and optical properties of Arg96, Glu222 and Gly67 variants of green fluorescent protein, Biochem. Biophys. Res. Commun. 332 (2005), 657-663.

[8] R.Y. Tsien, The green fluorescent protein, Annu. Rev. Biochem. 67 (1998), 509-544.

[9] L.F. Vallejo and U. Rinas, Strategies for recovery of active proteins through refolding of bacterial inclusion body proteins, Microb. Cell Fact. 3 (2004), 11. 


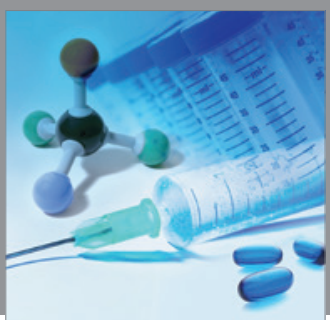

International Journal of

Medicinal Chemistry

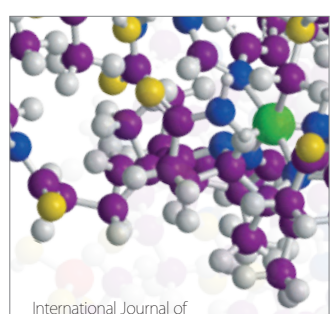

Carbohydrate Chemistry

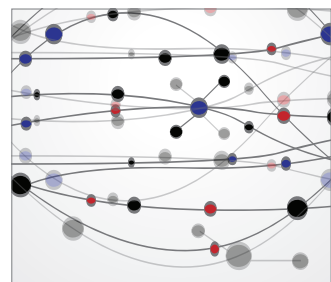

The Scientific World Journal
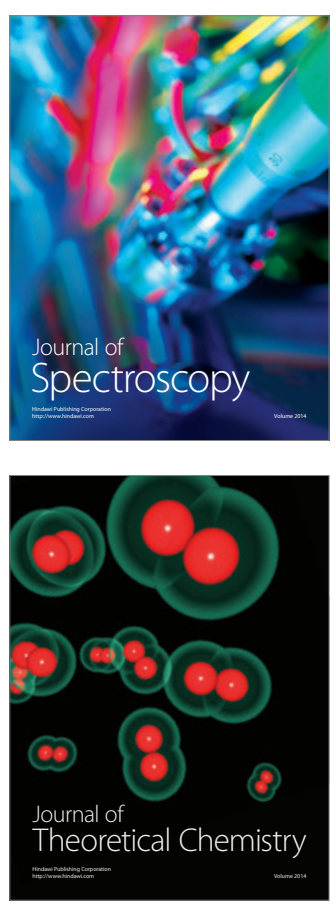
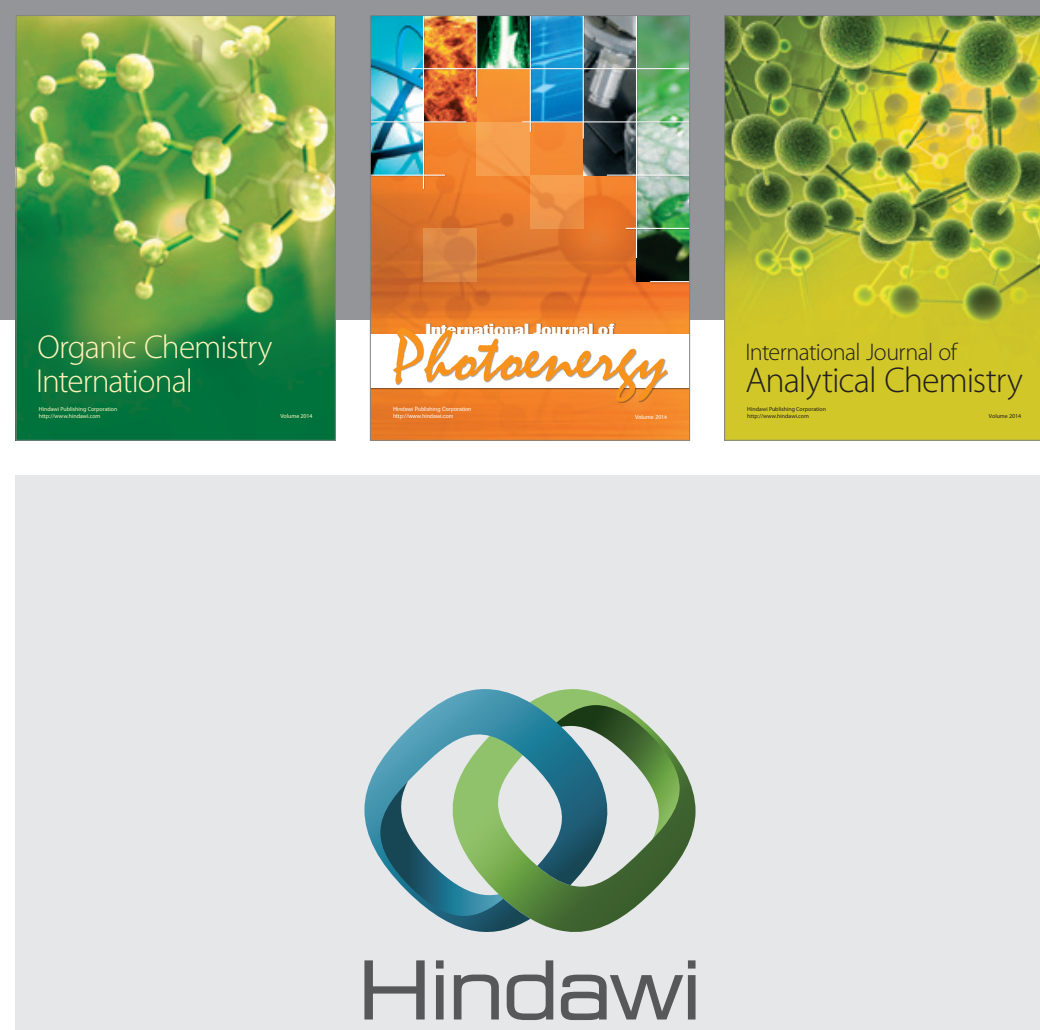

Submit your manuscripts at

http://www.hindawi.com
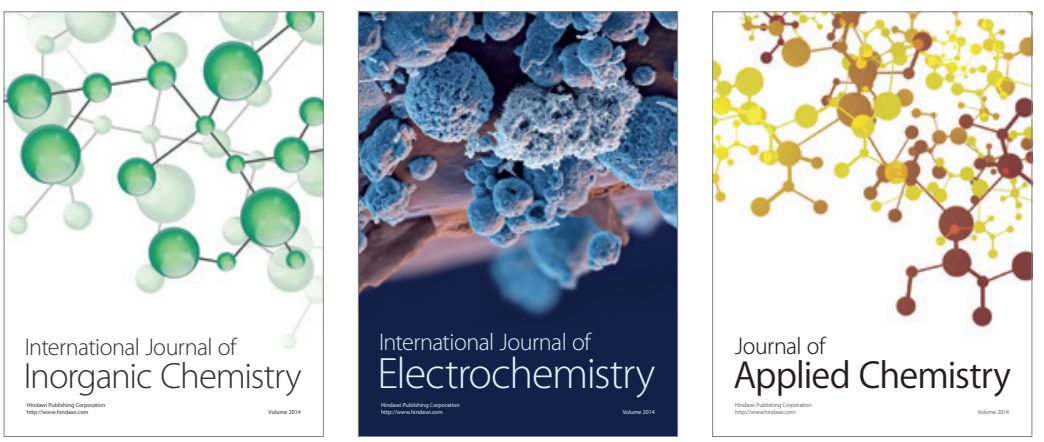

Journal of

Applied Chemistry
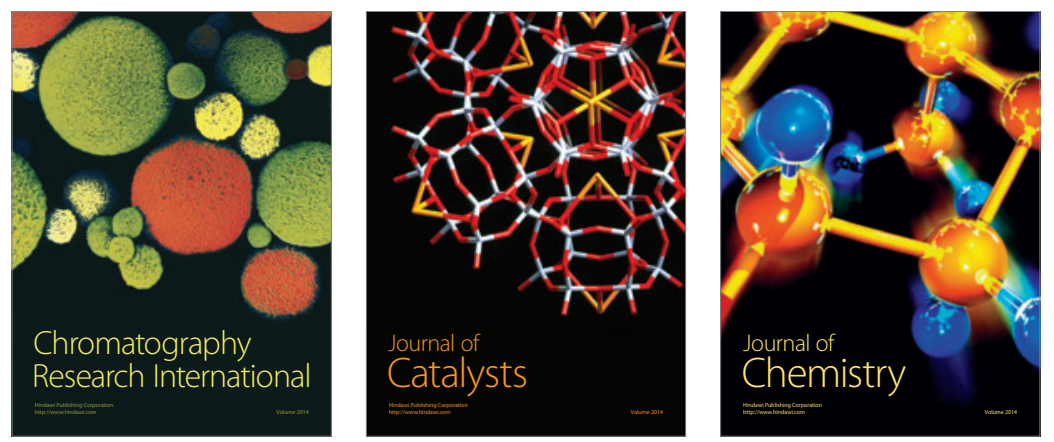
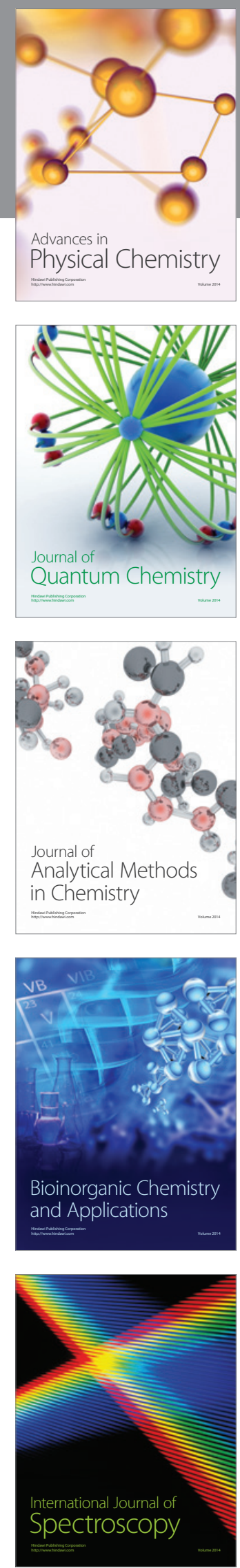